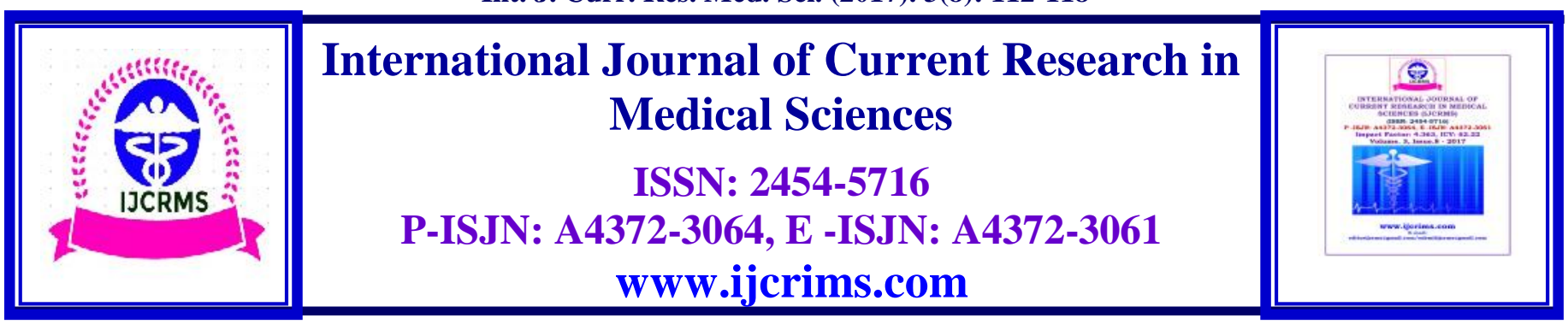

\title{
Histopathological examination of various lesions of gall bladder in routine 488 cholecystectomy specimens - A hospital based study.
}

\author{
*Ram Krishan Sharma, **Neeraj Bisht, ***N.S. Neki \\ *Assistant Professor, **Senior Resident, Department of Pathology, Govt. Medical College, \\ Amritsar, India, 143001 \\ ****Professor of Medicine, Govt. Medical College/ Guru Nanak Dev Hospital, Amritsar, India, 143001 \\ Corresponding Author: Dr. Neeraj Bisht, Senior Resident, Dept. of Pathology, Govt. Medical College, \\ Amritsar, India, 143001 \\ E-mail: neerajbisht478@gmail.com
}

\begin{abstract}
Disorders of gall bladder affect significant portion of population. Gall bladder is affected by inflammation, infection as well as benign and malignant conditions. Most (95\%) of gall bladder diseases are attributable to cholelithiasis (stone) where females are affected more than male. Early diagnosis and treatment greatly reduce themortality and morbidity. The aim of this article is to know the incidence, histopathological diagnosis and outcome of the gall bladder disease

This paper is based on one year experience in our hospital attached to Govt. Medical College, Amritsar. Over a period of one year, histopathological examination of 488 cholecystectomy specimens were done. Out of 488 cases ,there were $407(83.4 \%)$ females and $81(16.6 \%)$ males .In males $79 / 488(16.18 \%)$ cholecystectomy specimens were diagnosed as benign lesion and 02/488(0.40\%) were diagnosed as malignant lesions. In females 392//488 (80.32\%) cholecystectomy specimens were diagnosed as benign lesion and 15/488(3.07\%) were diagnosed as malignant lesions. Most common benign lesion among male and female was chronic cholecystitis with cholelithiasis $439 / 488(89.95 \%)$ respectively. Overall frequency of malignancy in this study was $3.47 \%$.
\end{abstract}

Keywords: Gall bladder, cholelithiasis, carcinoma.

\section{Introduction}

Disorders of the biliary tract affect a significant portion of the world's population. Over $95 \%$ of biliary tract disease is attributable to cholelithiasis (gallstones).The gallbladder is a surgically important organ of the body which may be affected by a variety of pathological processes.
It has a wide spectrum of diseases ranging from congenital anomalies, gallstones and its complications, non-inflammatory, inflammatory to the neoplastic lesions. Gallstones are the commonest biliary pathology and are major cause of morbidity and mortality. Gallstones present for 
a longer period predispose to carcinoma of gall bladder $^{[1]}$. Cholelithiasis is a common disorder affecting $10 \%$ to $20 \%$ of adult population. It is common among females. More than $95 \%$ of biliary tract disease is attributed to cholelithiasis. The prevalence of gallstones in Northern India is $4.1 \%$ comprising $1.9 \%$ in males and $5.5 \%$ in females. The prevalence varies with age, sex and ethnic group, most patients are unaware of the disease and remain asymptomatic for life. The current changes in lifestyles of individuals pertaining to indulgement in unhealthy fat-rich food, lack of exercise, obesity, sedentary lifestyles and various other factors have once again focused our attention to gall stones and diseases of the gall bladder. Gall bladder carcinoma ranks 5th in the gastrointestinal malignant tumors and due to non-specific clinical presentation, it is rarely diagnosed at an early stage $^{[2]}$. Carcinoma gallbladder though rare is the most common malignancy of the biliary tract. Women have a higher risk of developing gallbladder cancer than men ${ }^{[3,4]}$. The most important risk factor for gallbladder cancer(besides gender and ethnicity) is gallstone. Gallbladder cancer is a late presentation disease; hence the prognosis is poor and associated with highmortality rate. Several studies showed that routine histopathological examination of all cholecystectomy specimens is needed because of significant risk of incidental carcinoma. Incidental detection of gallbladder cancer in cholecystectomy specimen has been reported in 0.3 to $2 \%$ of all cholecystectomies performed for benign condition .It is important to study histopathological changes in order to determine the incidence, prevalence, and distribution of the lesions.

\section{Aims and objectives}

1. To study the range of histopathological lesions in routine cholecystectomy specimens.
2. To determine the age and sex distribution among patients with the lesions.

3. To ascertain the frequency of abnormalities.

\section{Materials and Methods}

\section{Source of data}

The present study was done on 488 cholecystectomy specimens received in the Department of Pathology at Government Medical College, Amritsar. Clinical details and histopathological data were retrieved from the hospital records. The surgically resected cholecystectomy specimens were examined macroscopically and two full thickness sections taken from fundus, body and neck of gall bladder. In cases with any evidence of gross abnormality, additional sections were taken. These tissue sections were subjected to routine processing and staining byhematoxylin and eosin stain. Microscopic examination was done to assess the type of histopathological lesions present

\section{Inclusion criteria}

1). All specimens of cholecystectomy.

\section{Exclusion criteria}

1). Specimens without any clinical details 2). Autolysed Specimens.

\section{Sample size}

A sample of 488 gallbladder specimens of cholecystectomy collected from Jan 2016 to Dec 2016 were taken for study purpose. 
Int. J. Curr. Res. Med. Sci. (2017). 3(8): 112-118

\section{Results and Observations}

Table 1 Distribution of study subjects according to sex

\begin{tabular}{|l|c|c|}
\hline \multicolumn{1}{|c|}{ Sex } & Number(n) & Percentage\% \\
\hline Male & 81 & $16.6 \%$ \\
\hline Female & 407 & $83.4 \%$ \\
\hline Total & 488 & $100 \%$ \\
\hline
\end{tabular}

Over a period of one year, histopathological examination of 488 cholecystectomy specimens were done. Out of 488 cases there were
407(83.4\%) females and 81(16.6\%) males, with male to female ratio 1:5.02.

Table 2 Distribution of study subjects according to age

\begin{tabular}{|l|c|c|c|c|}
\hline \multicolumn{1}{|c|}{ Age group in years } & $\begin{array}{c}\text { Male } \\
(\mathrm{n})\end{array}$ & $\begin{array}{c}\text { Percentage } \\
\%\end{array}$ & $\begin{array}{c}\text { Female } \\
(\mathrm{n})\end{array}$ & $\begin{array}{c}\text { Percentage } \\
\%\end{array}$ \\
\hline$<20$ & 6 & $1.22 \%$ & 16 & $3.27 \%$ \\
\hline $21-30$ & 11 & $2.25 \%$ & 78 & $15.98 \%$ \\
\hline $31-40$ & 12 & $2.45 \%$ & 111 & $22.74 \%$ \\
\hline $41-50$ & 17 & $3.48 \%$ & 115 & $23.56 \%$ \\
\hline $51-60$ & 23 & $4.71 \%$ & 55 & $11.27 \%$ \\
\hline $61-70$ & 12 & $2.45 \%$ & 26 & $5.32 \%$ \\
\hline $71-80$ & 0 & 0 & 5 & $1.02 \%$ \\
\hline$>80$ & 0 & 0 & 1 & $0.20 \%$ \\
\hline Total & 81 & $16.6 \%$ & 407 & $83.4 \%$ \\
\hline
\end{tabular}

In males maximum number of cases were in age group 41-60 years and in females maximum number of cases were in age group 31-50 years.

Table 3 Distribution of study subjects according to histopathology report

\begin{tabular}{|l|c|c|c|c|}
\hline \multicolumn{1}{|c|}{ Histology } & Male (n) & Percentage \% & Female (n) & Percentage \% \\
\hline Benign & 79 & $16.18 \%$ & 392 & $80.32 \%$ \\
\hline Malignant & 02 & $0.40 \%$ & 15 & $3.07 \%$ \\
\hline Total & 81 & $16.6 \%$ & 407 & $83.4 \%$ \\
\hline
\end{tabular}

In males $79 / / 488 \quad(16.18 \%)$ cholecystectomy specimens were diagnosed as benign lesion and $02 / 488(0.40 \%)$ were diagnosed as malignant lesions.In females $392 / / 488 \quad(80.32 \%)$ cholecystectomy specimens were diagnosed as benign lesion and 15/488(3.07\%) were diagnosed as malignant lesions. 
Int. J. Curr. Res. Med. Sci. (2017). 3(8): 112-118

Table 4 Distribution of study subjects with benign lesions according to age and sex.

\begin{tabular}{|l|c|c|c|c|}
\hline \multicolumn{1}{|c|}{ Age group in years } & $\begin{array}{c}\text { Male } \\
(\mathrm{n})\end{array}$ & $\begin{array}{c}\text { Percentage } \\
\%\end{array}$ & $\begin{array}{c}\text { Female } \\
(\mathrm{n})\end{array}$ & $\begin{array}{c}\text { Percentage } \\
\%\end{array}$ \\
\hline$<20$ & 6 & $1.22 \%$ & 16 & $3.27 \%$ \\
\hline $21-30$ & 11 & $2.25 \%$ & 78 & $15.98 \%$ \\
\hline $31-40$ & 11 & $2.25 \%$ & 109 & $22.74 \%$ \\
\hline $41-50$ & 17 & $3.48 \%$ & 106 & $23.56 \%$ \\
\hline $51-60$ & 23 & $4.71 \%$ & 54 & $11.27 \%$ \\
\hline $61-70$ & 11 & $2.25 \%$ & 24 & $5.32 \%$ \\
\hline $71-80$ & 0 & 0 & 4 & $1.02 \%$ \\
\hline$>80$ & 0 & 0 & 1 & $0.20 \%$ \\
\hline Total & 79 & $16.18 \%$ & 392 & $80.32 \%$ \\
\hline
\end{tabular}

In males benign lesions were more common in age group of 51-60 years followed by 41-50 years. In females benign lesion were more common in age group of 31-40 years followed by 41-50 years. Females are affected more than males.

Table 5 Distribution of study subjects with malignant lesions according to age and sex.

\begin{tabular}{|l|c|c|c|c|}
\hline Age group in years & $\begin{array}{c}\text { Male } \\
(\mathrm{n})\end{array}$ & $\begin{array}{c}\text { Percentage } \\
\%\end{array}$ & $\begin{array}{c}\text { Female } \\
(\mathrm{n})\end{array}$ & $\begin{array}{c}\text { Percentage } \\
\%\end{array}$ \\
\hline$<20$ & 0 & 0 & 0 & 0 \\
\hline $21-30$ & 0 & 0 & 0 & 0 \\
\hline $31-40$ & 1 & $0.20 \%$ & 2 & $0.40 \%$ \\
\hline $41-50$ & 0 & 0 & 9 & $1.84 \%$ \\
\hline $51-60$ & 0 & 0 & 1 & $0.20 \%$ \\
\hline $61-70$ & 1 & $0.20 \%$ & 2 & $0.40 \%$ \\
\hline $71-80$ & 0 & 0 & 1 & $0.20 \%$ \\
\hline$>80$ & 0 & 0 & 0 & 0 \\
\hline Total & 02 & $0.40 \%$ & 15 & $3.07 \%$ \\
\hline
\end{tabular}

In males frequency of malignancy was $0.4 \%$ and age group was between 31-40 years and 61-70 years. In females frequency of malignancy was
$3.07 \%$ and most commonly affects the age group 41-50 years followed by 61-70 years. Frequency of malignancy is more in females than males.

Table 6 Histopathology diagnosis of various benign lesions among study subjects.

\begin{tabular}{|l|c|c|c|c|}
\hline \multicolumn{1}{|c|}{ Diagnosis } & Male (n) & Percentage $\%$ & Female(n) & Percentage \% \\
\hline Chronic choelcystitis & 4 & $0.8 \%$ & 10 & $2.0 \%$ \\
\hline $\begin{array}{l}\text { Chronic cholecystitis } \\
\text { with cholelithiasis }\end{array}$ & 69 & $14.13 \%$ & 370 & $75.8 \%$ \\
\hline Cholesterosis & 0 & 0 & 1 & $0.2 \%$ \\
\hline $\begin{array}{l}\text { Acute on chronic } \\
\text { cholecystitis }\end{array}$ & 3 & $0.6 \%$ & 8 & $1.64 \%$ \\
\hline Eosinophilic cholecystitis & 1 & $0.2 \%$ & 0 & 0 \\
\hline $\begin{array}{l}\text { Xanthogranulomatous } \\
\text { cholecystitis }\end{array}$ & 2 & $0.4 \%$ & 3 & $0.6 \%$ \\
\hline Total & 79 & $16.18 \%$ & 392 & $80.32 \%$ \\
\hline
\end{tabular}


Most common benign lesion among male and female was chronic cholecystitis with cholelithiasis followed by chronic cholecystitis and acute or chronic cholecystitis.

Table 7 Histopathology diagnosis of various malignant lesions among study subjects.

\begin{tabular}{|l|c|c|c|c|}
\hline \multicolumn{1}{|c|}{ Diagnosis } & Male (n) & Percentage \% & Female(n) & Percentage \% \\
\hline $\begin{array}{l}\text { Mucinous } \\
\text { adenocarcinoma }\end{array}$ & 0 & 0 & 02 & $0.4 \%$ \\
\hline Papillary adenocarcinoma & 02 & $0.4 \%$ & 13 & $2.67 \%$ \\
\hline Total & 02 & $0.4 \%$ & 15 & $3.07 \%$ \\
\hline
\end{tabular}

In males frequency of adenocarcinoma was $0.4 \%$ and both the cases were of Papillary adenocarcinoma. In females frequency of adenocarcinoma was $3.07 \%$. Among the malignant cases 2 were of Mucinous adenocarcinoma and 13 cases were of Papillary adenocarcinoma.

\section{Discussion}

Gallbladder cancer continues to be a very rare entity. Even though some evidence suggests the possibility of diagnosing this malignant disease before pathology analysis, most centres continue to send every extracted gallbladder to the pathology department for its routine analysis .A sample of 488 gallbladder specimens of cholecystectomy collected from Jan 2016 to Dec 2016 were taken for this study purpose.

In this study, females outnumbered males. Out of 488 cases there were $407(83.4 \%)$ females and $81(16.6 \%)$ males. Female predominance is also reported by similar studies ${ }^{[5,6]}$. The age group ranging from 19 to 80 years, is slightly higher than that reported in other studies ${ }^{[7]}$. In this study maximum number of cases in males were in age group of 41-60 years and in females maximum number of cases were in age group of 31-50 years.

The most common histopathological finding in our study was chronic cholecystitis with cholelithiasis 439/488(89.95\%). A similar study by Memon ${ }^{[8]}$ also reports chronic cholecystitis as major histopathological finding, identified in $64.8 \%$ cases.
Khoo et al reported that majority of the non neoplastic lesions (76.8\%) of gall bladder occurred in 3rd to 5th decades of life which is comparable with present study. ${ }^{[9]}$

In this study, carcinoma of gallbladder was found in 17 cases (3.47\%). The incidence of gallbladder malignancy in this series was considerably low compared to other studies, which show an incidence varying from 6.9 to 12 per cent ${ }^{[10,11,12]}$. Low incidence of malignancy in our patients can also be attributed to increased acceptance and early reporting for laparoscopic cholecystectomy due to resort to day-care surgery at our institution. Samad ${ }^{[13]}$ reports an incidence of $1.1 \%$ of malignancy in patients who underwent cholecystectomy for presumed chronic cholecystitis with cholelithiasis. In our study ,In males 79//488 (16.18\%) cholecystectomy specimens were benign lesion and $02 / 488(0.40 \%)$ were malignant lesions. In females 392/488 $(80.32 \%)$ cholecystectomy specimens were benign lesion and 15/488(3.07\%) were malignant lesions.

In our study, frequency of adenocarcinoma in males was $0.4 \%$ and age group was between 3140 years and 61-70 years. In females frequency of adenocarcinoma was $3.07 \%$ and most commonly affects the age group of 41-50 years followed by $61-70$ years. Frequency of malignancy is more in females than males. Misra $\mathrm{S}$ et $\mathrm{al}^{[14]}$ shows that the incidence of gallbladder cancer is very low . It is known that more than $90 \%$ of patients are over 50-60 years old, then the incidence of gallbladder cancer among people under 60 would be around $0.2-0.3 \%$. Even though the percentage is extraordinarily low, it would be unacceptable to miss a neoplasm in a young patient. 
Pandey et al ${ }^{[15]}$ reported in his study that out of 69 patients 51(73.9\%) shows adenocarcinoma, 12 (17.4\%) shows mucinous carcinoma, 6(8.7\%) shows papillary adenocarcinoma on histopathologicalexamination.In our study, In males frequency of adenocarcinoma was $0.4 \%$ and both the cases were of papillary adenocarcinoma. In females frequency of adenocarcinoma was $3.07 \%$. Among malignant cases in females 2 were of mucinous adenocarcinoma and 13 cases were of papillary adenocarcinoma.

Chattopadhyay et al ${ }^{[16]}$ noted that in23 postcholecystectomy specimen $12(52.1 \%)$ have gallstones, $7(30.4 \%)$ have cholesterol polyps, $3(13 \%)$ haveadenocarcinoma, $1(4.3 \%)$ has normal features of gallbladder on histology. In the present study, among all the lesions of gallbladder, chronic calculous cholecystitis (46\%) was the commonest histological finding which is comparable with our study.

Awasti $\mathrm{N}^{[17]}$ in his study found that,out of total 732 cholecystectomies, gall stones were present in $697(95.2 \%)$ patients, finding that was consistent with our study. Females accounted for $72 \%$ of total patients with male to female ratio being $1: 2.6$. In our study male to female ratio is $1: 5.02$ which is higher as compared to Awasti $\mathrm{N}^{[17]}$.The most common histopathological finding in Awasti $\mathrm{N}^{[17]}$ study was chronic cholecystitis, seen in 711 cases out of 732 (97.1\%), which is consistent with our study. Xanthogranulomatous change, acute cholecystitis and empyema were seen in $1.8 \%$, $0.8 \%$ and $0.3 \%$ cases respectively. In our study Xanthogranulomatous change, acute cholecystitis and empyema were seen in $1.0 \%, 2.24 \%$ and $0 \%$ cases respectively.

Kumbhakar D et $\mathrm{al}^{[18]}$ found that Chronic cholecystitis $(86.25 \%)$ was the most common finding followed by cholesterolosis $(7.50 \%)$ and various other mucosal pathologies of gallbladder. Female to male ratio was $4.71: 1$. Frequency of gallbladder cancer was $1.25 \%$. In our study chronic cholecystitis with cholelithiasis 439/488 $(89.95 \%)$ was the most common finding which is in consistent with Kumbhakar D et $\mathrm{al}^{[18]}$.In our study, carcinoma of gallbladder was found in 17 cases $(3.47 \%)$.

Wren SM et $\mathrm{al}^{[19]}$ in his study found that the incidence of malignancy was $0.25 \%$ and dysplasia was $0.70 \%$. In our study, carcinoma of gallbladder was found in 17 cases $(3.47 \%)$ which is higher as compared to this study. The most common pathological findings included chronic cholecystitis in $89 \%$ and cholelithiasis in $81 \%$ of specimens.In our study chronic cholecystitis with cholelithiasis $439 / 488$ (89.95\%) was the most common finding which is in consistent with Wren SM et al ${ }^{[19]}$.

\section{Conclusion}

Gallbladder disease poses to be a common surgical health issue requiring cholecystectomy world wide. Most $(95 \%)$ of gall bladder disease are attributable to cholelithiasis (stone) where females are affected more than male. Early diagnosis and treatment greatly reduce the mortality and morbidity. Thorough sampling of the cholecystectomy specimens and routine histopathological examination is of utmost importance to detect non neoplastic complications and incidental gallbladder cancer. The main strength of this study is that it gives the most comprehensive picture of different histopathological pattern and frequency of gall bladder cancer of cholecystectomy specimens done in our institute. The major limitations of this study include its small sample size and the short study period.

\section{Source of funding: Nil}

Conflict of interest: None declared

\section{References}

1.Nordenstedt $H$, Mattsson F, El-Serag $H$, Lagergren JJ. Gallstones and cholecystectomy in relation to risk of intra- and extrahepatic cholangiocarcinoma.Br J Cancer. 2012 Feb 28;106(5):1011-5. DOI: 10.1038/bjc.2011.607. Epub 2012 Jan 12. 
2.Byars and K. Pursnani, "An Alternative Approach to Sending All Gallbladders for Histology Following Cholecystectomy?," Surgical Science. 2012; 3(1): 15-20.

3. Chin KF, Mohammad AA, Khoo YY.Impact of routine histopathological examination on cholecystectomy specimens from an Asian demographic.Ann R Coll Surg Engl. 2012; 94: 165-69.

4.Khan F, Manzoor A, Haq MB.Histological examination ofcholecystectomy specimens. Journal of Rawalpindi Medical College (JRMH); 2014; 18(2): 240-242.

5.Channa NA, Soomro AM, Ghangro AB. Cholecystectomy is becoming an increasingly common operation in Hyderabad and adjoining areas. Rawal Med J. 2007; 32(2):128-130.

6.Murshid KR. Symptomatic gallstones: a disease of young Saudi women. Saudi J Gastroenterol. 1998; 4(3):159-162.

7.Ali SA, Tahir SM, Soomoro AG, Siddiqui AJ, Memon AS. Open cholecystectomy without intraperitoneal drainage. J Ayub Med Coll Abbottabad. 2010;22(2):29-31.

8.Memon W, Khanzada TW, Samad A, Kumar B. Histopathology spectrum of gallbladder specimens after cholecystectomy. Pak J Med Sci. 2011; 27(3):533-536.

9.Khoo J J, Misron NA; A Clinicopathological study of nine cases of gallbladder carcinoma in 1122cholecystectomies in Johor, Malaysia. Malaysian J Pathol 2008; 30(1): 21- 26.

10.Siddiqui FG, Soraya NS. An audit of cholecystectomy specimens. J Surg Pak. 2002;7:18-21.

11.Ayyaz M, Waris M, Fahim F. Presentation and etiological factors of cancer gall bladder in patients undergoing cholecystectomies at Mayo Hospital, Lahore. Ann King Edward Med Coll. 2001; 7: 138-140.

12.Nawaz T, Khan RA, Malik AZ, Anwar I, Younus $M$. Incidence of carcinoma gall bladder in cholelithiasis. Pak J Surg. 2000;16:33-36.

13.Samad A. Gall bladder carcinoma in patients undergoing cholecystectomy for cholelithiasis. J Pak Med Assoc. 2005; 55:497-499.

14.Misra S, Chaturvedi A, Misra NC, Sharma ID. Carcinoma of the gallbladder. Lancet Oncol. 2003;4(3):167-176.

15.Pandey M, Pathak A K, Gautam A, Aryya NC, Shukla VK; Carcinoma of The Gallbladder: A Retrospective Review of 99 Cases; Digestive Diseases And Sciences 2001; 46 (6): 11451151.

16.Chattopadhyay D, Lochan R, Balupuri S, Gopinath BR, Wyne KS; Outcome Of Gallbladder Polypoidal Lesions Detected By Transabdominal Scanning: A Nine Year Experience, World Journal Of Gastroenterology 2005; 11(14) :2171-2173.

17.AwasthiN.A retrospective histopathological study of cholecystectomies. IJHAS, 2015; 4 (3): 203-206

18.Kumbhakar D;A Histopathological Study of Cholecystectomy Specimens. JMSCR 2016; 4(7): 11234-11238.

19.Wrenn SM, Peter WC, Jaish WA. Histopathological examination of specimen following cholecystectomy: Are we accepting resect and discard?. Surgical Endoscopy; 2017; 31( 2): 586-593.

\begin{tabular}{|c|c|}
\hline \multicolumn{2}{|c|}{ Access this Article in Online } \\
\hline 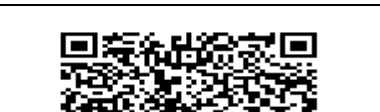 & $\begin{array}{l}\text { Website: } \\
\text { www.ijcrims.com }\end{array}$ \\
\hline 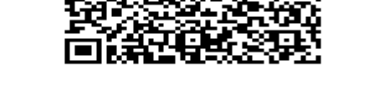 & \multirow{2}{*}{$\begin{array}{l}\text { Subject: } \\
\text { Medical Sciences }\end{array}$} \\
\hline Quick Response Code & \\
\hline
\end{tabular}

How to cite this article:

Ram Krishan Sharma, Neeraj Bisht, N.S. Neki. (2017). Histopathological examination of various lesions of gall bladder in routine 488 cholecystectomy specimens - A hospital based study.. Int. J. Curr. Res. Med. Sci. 3(8): $112-118$.

DOI: http://dx.doi.org/10.22192/ijcrms.2017.03.08.017 